\title{
MODERN APPROACHES TO THE INTERPRETATION OF CERTAIN HUMAN RIGHTS
}

\author{
Tatyana V. Goverdovskaya \\ Astrakhan State University, Astrakhan, Russian Federation
}

\begin{abstract}
Introduction: the article is devoted to the consideration of the practice of the European Court of Human Rights, which forms a new interpretation of some traditional human rights, or which gives a new content to already known legal categories. For this purpose, the author analyzed several decisions by the European Court of Human Rights on the rights of interest to the author, as well as the right to life in the context of euthanasia and the marriage right. When using such methods of scientific knowledge as the method of analysis and interpretation of the legal norms, it was possible to identify some of the innovations that the European Court of Human Rights brings to the content of these rights. Results: it is pointed out that the international human rights treaties, both universal and regional, do not contain the specific content of the "right to life", only proclaiming it, but not disclosing its content, which has recently led to a broad interpretation of this right in an attempt to legalize euthanasia as a component of the right to life. The similar gaps exist in the interpretation of the marriage right, since it is only indicated that both men and women who have reached the formal requirements of the national law are entitled to form a family and enter into marriage. The lack of a clear indication of the sex of the parties leads to numerous complaints to the European Court of Human Rights about the violation of this right in respect of same-sex unions. Conclusions: it is safe to assume that the European Court of Human Rights will soon adopt a Resolution obliging the respondent state to regulate the legal procedures for the exercise of the right to life in the context of euthanasia in relation to such categories as personal dignity and quality of life. Not recognizing euthanasia as a component of the right to life, the Court, however, is actively arguing about the interference with privacy and the violation of the dignity of a terminally ill person with significant physical limitations in the prohibition of euthanasia. This assumption is acceptable due to the fact that initially complaints from same-sex unions were considered as unacceptable, and now this type of cohabitation is recognized as a family life and has required the legal regulation since 2015.

Key words: human rights, the European Court of Human Rights, euthanasia, personal dignity, quality of life, the right to life, the right to marriage, same-sex unions, legal regulation.
\end{abstract}

Citation. Goverdovskaya T.V. Modern Approaches to the Interpretation of Certain Human Rights. Legal Concept, 2018, vol. 17, no. 4, pp. 71-77. DOI: https://doi.org/10.15688/lc.jvolsu.2018.4.10

УДК 341.01

Дата получения статьи: 31.07.2018

ББК 67.91

Дата принятия статьи: 22.10.2018

\section{СОВРЕМЕННЫЕ ПОДХОДЫ В ТРАКТОВКЕ НЕКОТОРЫХ ПРАВ ЧЕЛОВЕКА}

\section{Татьяна Владимировна Говердовская}

Астраханский государственный университет, г. Астрахань, Российская Федерация формируется новое толкование некоторых традиционных прав человека, либо в которой придается новое содержание уже известным правовым категориям. С этой целью автор проанализировал несколько постановлений Европейского Суда по правам человека, по интересующим автора правам, таким как право на жизнь в контексте эвтаназии и право на вступление в брак. При использовании таких методов научного познания, как метод анализа и толкования правовых норм, удалось определить некоторые новшества, которые Европейский Суд по правам человека вносит в содержание указанных прав. Результаты: указывается, что международные договоры о правах человека как универсального, так и регионального характера не содержат конкретного содержания «права на жизнь», лишь провозглашая его, но не раскрывая его содержа- 


\section{ТЕОРИЯ И ПРАКТИКА ГОСУДАРСТВЕННО-ПРАВОВОГО РАЗВИТИЯ}

ния, что в последнее время приводит к расширительному толкованию данного права в попытках легализовать эвтаназию как составляющую права на жизнь. Аналогичные пробелы содержатся и при толковании права на вступление в брак, так как указано лишь, что и мужчинам и женщинам, достигшим формальных требований национального законодательства, предоставляется право создать семью и заключить брак. Отсутствие четкого указания на половую принадлежность сторон приводит к многочисленным жалобам в Европейский Суд по правам человека о нарушении данного права в отношении однополых союзов. Выводы: можно с уверенностью полагать, что в скором времени Европейский Суд по правам человека примет Постановление, в котором обяжет государство-ответчика регламентировать правовые процедуры по осуществлению права на жизнь в контексте эвтаназии в связи с такими категориями, как достоинство личности и качество жизни. Не признавая эвтаназию как составляющую права на жизнь, Суд, тем не менее, активно говорит о вмешательстве в личную жизнь и о нарушении достоинства смертельно больного человека с существенными физическими ограничениями при запрете эвтаназии. Такое предположение допустимо в связи с тем, что изначально жалобы от однополых союзов рассматривались как неприемлемые, а в настоящее время такой вид сожительства признается семейной жизнью и с 2015 г. требует правовой регламентации.

Ключевые слова: права человека, Европейский Суд по правам человека, эвтаназия, достоинство личности, качество жизни, право на жизнь, право на вступление в брак, однополые союзы, правовая регламентация.

Цитирование. Говердовская Т. В. Современные подходы в трактовке некоторых прав человека // Legal Concept $=$ Правовая парадигма. -2018 . - T. 17, № 4. - C. 71-77. - DOI: https://doi.org/10.15688/lc.jvolsu.2018.4.10

\section{Введение}

Институт прав и свобод человека и гражданина стал неотъемлемой категорией современного общества и правового государства. Перечни прав и свобод содержатся в различных международно-правовых документах и нормах национального законодательства. При этом каталог прав и свобод постоянно расширяется и изменяется в связи с развитием общества, науки и техники, появляются новые поколения прав человека. Институт прав и свобод человека и гражданина не статичен, а является постоянно развивающейся категорией.

Традиционно считается, что первые представления о правах человека появились в V-VI вв. до н. э., когда в древних полисах, прежде всего Афинах, появилась категория «гражданство», предоставившая определенные привилегии некоторым членам общества [4]. Наиболее древним «документом», содержащим указание на некоторые права человека, признают Манифест Кира Великого, который содержал мнение царя о необходимости отмены рабства и свободе вероисповедания. Еще одним историческим памятником, содержащим некоторые современные права человека, является Великая Хартия вольностей 1215 г., которая предусматривала возможность покидать страну и свободно в нее возвращаться, допустимость назначить наказание только по приговору суда, а также закрепила институт частной собственности и ее неприкосновенность. Принятые в Англии Хабеас Корпус Акт 1679 г. и Билль о правах 1689 г. заложили ряд политических и личных прав, а также расширили процессуальные гарантии. «Первым юридическим документом в истории, который провозгласил всеобщие права человека, считается Билль о правах (июнь 1776 г.), принятый конгрессом народных представителей штата Вирджиния в Северной Америке. Следующим документом стала Декларация независимости (июль 1776 г.), принятая Континентальным конгрессом тринадцати североамериканских колоний. Затем Конституция США (1787) и знаменитые десять поправок, известные как Билль о правах (1791)» [4]. Знаковым документом для всей концепции прав и свобод человека и гражданина необходимо признать Декларацию прав человека и гражданина 1789 г,, которая провозглашает неотчуждаемость и неотделимость прав человека. Французская декларация положила начало тенденции включения прав человека во внутренние публичные акты. Bсе перечисленные документы относятся в большей степени к первому поколению прав человека.

Появление социальных, экономических и культурных прав человека потребовало их юридического закрепления, что и было сделано в 1948 г. принятием Всеобщей Декларации прав человека, которая закрепила на уни- 
версальном уровне права и свободы человека, включая и второе поколение прав. Несмотря на то что Декларация носила рекомендательный характер для государств-членов, в настоящее время ее положения рассматриваются как общеобязательные и когентные, а сама Декларация стала нормой обычного международного права. Логичным развитием положений Всеобщей Декларации стало принятие Международных Пактов о правах в 1966 г., которые не только дополнили каталог прав и свобод, изложенный в Декларации, но и предусмотрели контрольный механизм за соблюдением государствами-участниками перечисленных прав.

Международное сообщество не только принимает документы «широкой сферы» в области прав человека, но и конкретизирует, «сужает» права человека для отдельных категорий, например детей, женщин, инвалидов.

Помимо универсальных документов, регламентирующих права и свободы человека и гражданина, необходимо выделить и региональные договоры, которые играют значительную роль не только в осуществлении прав человека, но и в трактовании самих прав. К наиболее авторитетным следует отнести Африканскую Хартию прав человека и народов, которая в ст. 16 провозглашает право каждого человека на максимально возможный уровень психического и физического здоровья, а в ст. 23 провозглашается право на национальную и международную безопасность и мир [12]. Американская Конвенция о правах человека, в свою очередь, в ст. 4 указывает на обязанность государства защищать право на жизнь, возникающее с момента зачатия, то есть при расширительном толковании данной нормы можно предположить, что Конвенция регламентирует права эмбриона.

Однако для целей данной статьи наибольшее значение имеет Конвенция о защите прав человека и основных свобод 1950 г. и предусмотренный ею Европейский Суд по правам человека, который рассматривает жалобы от граждан государств-участников Конвенции о несоблюдении ее положений в конкретной стране, а также дает трактовку ее положений, а точнее содержания некоторых прав и свобод при вынесении решений по конкретным делам.

\section{Право на жизнь}

Каждый человек имеет право на жизнь согласно ст. 3 Всеобщей Декларации прав человека [1]. В соответствии со ст. 2 Европейской Конвенции «право каждого лица на жизнь охраняется законом. Никто не может быть умышленно лишен жизни иначе как во исполнение смертного приговора, вынесенного судом, а также при защите любого лица от противоправного насилия, при осуществлении законного задержания или предотвращения побега, в случае подавления бунта или мятежа в соответствии с законом» [2]. Согласно ст. 6 Международного Пакта о гражданских и политических правах право на жизнь является неотъемлемым правом каждого человека, которое охраняется законом [5]. При этом необходимо подчеркнуть, что ни один из указанных документов не содержит толкования того, в чем же заключается право на жизнь. Лишь Всеобщая Декларация после права на жизнь указывает также право на свободу и личную неприкосновенность, что при расширительном толковании позволяет предположить, что, таким образом, человеку предоставляется возможность самостоятельно определять момент ее (жизни) окончания в соответствии с предоставленной свободой. И именно этот нюанс позволяет в последнее время говорить об эвтаназии как о составляющем элементе предоставленного каждому человеку права на жизнь.

Эвтаназия - прекращение жизни неизлечимо больного человека, который испытывает мучения. В подавляющем большинстве стран мира и активная, и пассивная эвтаназии находятся под запретом. Тем не менее жалобы, связанные с желанием тяжелобольных людей прибегнуть к эвтаназии или ассистированному самоубийству, поступают в Европейский Суд и из стран, где подобные действия находятся вне закона.

В Европейский Суд было подано несколько жалоб о нарушении ст. 2 Конвенции, то есть о нарушении права на жизнь в контексте запрета ассистированного самоубийства или при прекращении искусственного питания и гидратации. Так, в наиболее известном деле Претти против Соединенного Королевства адвокат г-жи Претти заявил от ее имени, «что статья 2 


\section{ТЕОРИЯ И ПРАКТИКА ГОСУДАРСТВЕННО-ПРАВОВОГО РАЗВИТИЯ}

Конвенции защищает не саму жизнь, а право на жизнь. Целью этой статьи Конвенции является защита людей от третьих лиц (государства и органов государственной власти). Однако эта статья Конвенции признает, что люди сами должны решать, жить им или нет, и тем самым защищает право человека на самоопределение в вопросах жизни и смерти. Таким образом, человек может отказаться от лечения, направленного на то, чтобы спасти его жизнь или отсрочить наступление смерти. Он может принять решение покончить с собой, не нарушая при этом закон. Статья 2 Конвенции признает за человеком это право. Большинство людей хотят жить, но некоторые желают умереть, и статья 2 Конвенции защищает оба этих права» [6]. Несмотря на вполне логичные аргументы представителя госпожи Претти, Европейский Суд не допускает расширительного толкования данной статьи, и не усматривает возможности признать право на смерть, как закономерное следствие права на жизнь. И более того, обеспечить данному «праву» юридическую защиту. Так, в решении по указанному делу Европейский Суд делает следующее заключение: «из статьи 2 Конвенции нельзя вывести права на смерть ни от руки третьего лица, ни с помощью какого-либо органа государственной власти» [6]. При этом в деле Кох против Германии отмечается, что заявление «затрагивает фундаментальные вопросы, связанные с желанием пациента самостоятельно принимать решения относительно прекращения собственной жизни, которые представляют всеобщий интерес, выходящий за пределы личности и интересов заявителя и его покойной супруги» [7]. Не признавая «права на смерть», Европейский Суд выделяет такое понятие, как качество жизни. «Никоим образом не отрицая принцип священности жизни, охраняемой Конвенцией, Европейский Суд считает, что в эпоху активного развития медицины и увеличившейся продолжительности жизни многие люди боятся, как бы их не заставили доживать до глубокой старости или до состояния крайней физической или умственной беспомощности, что находится в противоречии с глубоко укоренившимися идеями самоидентичности и индивидуальности личности» [6]. В ряде решений Европейский Суд отмечает, что запрет эвтаназии в ка- кой бы то ни было форме может быть рассмотрен как вмешательство государства в реализацию права на уважение личной жизни, которая включает в себя широкий спектр правомочий. Право на уважение частной и семейной жизни иногда может «включать в себя аспекты физической и социальной самоидентификации человека». Несмотря на то что «право на смерть» не выводится из основных положений статьи 2 Конвенции, Европейский Суд рассматривает принцип независимости личности, как один из базовых принципов при толковании Конвенции и вынесении соответствующих решений. Как указывается в решении по делу Претти против Соединенного Королевства, «Европейский Суд должен подходить к толкованию Конвенции, являющейся живым организмом, гибко и динамично. В то же время любое толкование Конвенции должно соответствовать ее основным целям и ее внутренней непротиворечивости как системы защиты прав человека» [6].

«Европейский Суд отмечает, что способность строить свою жизнь по собственному усмотрению может также включать в себя возможность предпринимать действия, которые считаются физически или морально вредными или опасными для тех, кто их совершает. Так, оказание медицинской помощи совершеннолетнему пациенту, находящемуся в ясном рассудке, без его согласия, являлось бы настолько серьезным посягательством на физическую целостность личности, что оно могло бы затронуть права, охраняемые пунктом 1 статьи 8 Конвенции. Национальное право признает, что человек может реализовать свое решение покончить с собой, отказавшись продолжать лечение, которое могло бы отсрочить наступление смерти» [6].

Таким образом, можно предположить, что Европейский Суд по правам человека предусматривает возможность для человека умереть достойно, не выделяет соответствующего «права на смерть». При этом в жалобах, связанных с прекращением процедур, направленных на искусственное поддержание жизни, как нарушающих основные права человека, Европейский Суд предоставляет государствам широкую автономию в определении пределов продолжения или прекращения искусственного поддержания жизни с учетом 
положений ст. 2 и ст. 8 Конвенции [8]. В особом мнении ряда судей по жалобе Ламбер против Франции содержится положение о недопустимости прекращения мер, направленных на искусственное поддержание жизни. В этом же документе задается один из важнейших вопросов в данном контексте: «Если человек уже не имеет никакой дальнейшей пользы или значения для общества, на самом деле он уже не человек, а имеет только биологическую жизнь?» [11]

\section{Право на вступление в брак}

Статья 16 Всеобщей Декларации прав человека предусматривает возможность мужчин и женщин, которые достигли совершеннолетия, вступать в брак и основывать свою семью без дискриминации по различным признакам [1]. Международный Пакт о гражданских и политических правах в ст. 23 также признает за мужчинами и женщинами, достигшими брачного возраста, право основывать свою семью путем вступления в брак [5]. Европейская Конвенция 1950 г. также предусматривает, что «мужчины и женщины, достигшие брачного возраста, имеют право вступать в брак и создавать семью в соответствии с национальным законодательством, регулирующим осуществление этого права» [2]. «В конце XX начале XXI века в рамках европейской системы защиты прав человека стали актуализироваться вопросы недопустимости дискриминации по признакам сексуальной ориентации и гендерной идентичности» [3], в том числе и при заключении брака. Возможно, увеличение числа жалоб связано с тем, что ст. 12 Европейской Конвенции, как и аналогичные нормы других международных документов по вопросам брака, не содержит четкого указания на то, что брак может быть заключен только в том случае, когда одной стороной является мужчина, а второй - женщина. Международные же договоры содержат лишь указание, что правом на вступление в брак обладают как мужчины, так и женщины, что при расширительном толковании может быть использовано для подтверждения прав однополых союзов на создание семьи и заключение брака.

Первоначально жалобы, подаваемые однополыми партнерами в связи с нарушени- ем их прав на вступление в брак или на уважение частной и семейной жизни, признавались Европейским Судом неприемлемыми. Однако в деле Шальк и Копф против Австрии длительные и стабильные отношения заявителей были признаны «семейной жизнью» [9], что предоставило возможность защиты такими союзами своих прав на основании ст. 8 Европейской Конвенции. Суд не усмотрел нарушения ст. 12 Конвенции, но допускает, что право на вступление в брак может трактоваться расширительно и применяться к однополым лицам, но в строгом соответствии с нормой статьи, то есть на внутригосударственном уровне. Подобная позиция Европейского Суда подтверждается и рядом других дел, например Гас и Дюбуа против Франции, Шапин и Шарпентьер против Франции. Подтверждая подобное положение, Европейский Суд отметил, что «национальным властям виднее, как следует оценивать общественную необходимость в этом вопросе и отвечать на нее, учитывая, что понятие брака имеет глубоко укорененные социальные и культурные коннотации, которые сильно различаются в зависимости от общества» [9].

При этом в 2015 г. Европейский Суд по правам человека вынес одно из знаковых решений по делу Ольяри и другие против Италии, обязав Италию принять соответствующие законодательные нормы на национальном уровне с тем, чтобы у заявителей и аналогичных им лиц появились специальные правовые нормы, регулирующие обеспечение признания и защиты их союза [10].

\section{Выводы}

Таким образом, можно смело утверждать, что рассмотренные при написании статьи вопросы и проблемы, изложенные в жалобах заявителей, весьма актуальны, и будут оставаться таковыми еще достаточно продолжительное время в силу сложного переплетения морально-этических, духовных и политико-правовых вопросов при регулировании права на жизнь и права на вступление в брак. Европейский Суд неоднократно подчеркивал, что Конвенция - это живой организм, который должен отвечать изменениям, происходящим в обществе в связи с развитием науки, техники и изменением миро- 


\section{ТЕОРИЯ И ПРАКТИКА ГОСУДАРСТВЕННО-ПРАВОВОГО РАЗВИТИЯ}

воззрения по некоторым вопросам. Недопустимо оставлять без внимания и тем более правового регулирования ряд проблем и процессов, которые происходят в обществе.

Подчеркивая абсолютную недопустимость оказания медицинской помощи вменяемому совершеннолетнему пациенту без его согласия, многократно апеллируя к качеству жизни, ссылаясь на возможные нарушения прав человека на достоинство и уважение личной жизни при запрете эвтаназии, по мнению автоpa, Европейский Суд по правам человека в конечном итоге примет Постановление, в котором рекомендует государству регламентировать права смертельно больных лиц с существенными физическими ограничениями для реализации их права на достоинство в контексте эвтаназии или ассистированного самоубийства. В силу «прецедентности» европейского права это решение будет иметь широкий резонанс. В меньшей степени это отразится на России согласно Постановлению Конституционного Суда от 14 июля 2015 года.

Автор уверен в том, что Европейский Суд по правам человека вынесет соответствующее Постановление по правам лиц на достоинство в контексте эвтаназии и ассистированного самоубийства, исходя из того, что первоначально признавая жалобы однополых лиц о нарушении их прав на вступление в брак неприемлемыми из-за отсутствия «семейной жизни», спустя 60 лет однополые союзы стали трактоваться как семья. А в 2015 г., оставляя вопрос предоставления однополым лицам права заключать брак на усмотрение самого государства, Европейский Суд обязал на внутригосударственном уровне в любом случае обеспечить правовую регламентацию подобных союзов.

\section{СПИСОК ЛИТЕРАТУРЫ}

1. Всеобщая декларация от 10 декабря 1948 г. // Официальный сайт ООН. - Электрон. текстовые дан. - Режим доступа: http://www.un.org/ru/ documents/decl_conv/declarations/declhr (дата обращения: 09.08.2018). - Загл. с экрана.

2. Европейская конвенция от 4 ноября 1950 г. // Бюллетень международных договоров. - 2001. № 3 (Март).

3. Избранные решения Европейского Суда по правам человека. Вопросы сексуальной ориента- ции и гендерной идентичности. С. 4. - Электрон. текстовые дан. - Режим доступа: https://mhg.ru/ sites/default/files/files/izbrre.pdf (дата обращения: 11.08.2018). - Загл. с экрана.

4. Киричёк, Е. В. Становление и развитие прав и свобод человека и гражданина: философско-правовое измерение / Е. В. Киричёк // Юридическая наука и правоохранительная практика. - 2011. № 2 (16). - С. 15 .

5. Международный пакт о гражданских и политических правах от 16 декабря 1966 г. // Библиотечка Российской газеты. - 1999. - № 22-23.

6. Постановление Европейского Суда по правам человека по делу «Претти против Соединенного Королевства» от 29 апреля 2002 г. - Электрон. текстовые дан. - Режим доступа: http://europeancourt.ru/ uploads/ECHR_Pretty_v_the_United_Kingdom 29_04_2002.pdf (дата обращения: 15.08.2018). - Загл. с экрана.

7. Постановление Европейского Суда по правам человека по делу «Кох против Германии» от 19 июля 2012 г. // Правосудие. Судебная практика России. - Электрон. текстовые дан. - Режим доступа: http://www.pravosudie.biz/187604 (дата обращения: 31.08.2018). - Загл. с экрана.

8. Постановление Европейского Суда по правам человека по делу «Ламбер и другие против Франции» от 5 июня 2015 г. // Правосудие. Судебная практика России. - Электрон. текстовые дан. - Режим доступа: http://www. pravosudie.biz/049941 (дата обращения: 27.08.2018). - Загл. с экрана.

9. Постановление Европейского Суда по правам человека по делу «Шальк и Копф против Австрии» от 24 июня 2010 г. - Электрон. текстовые дан. - Режим доступа: http://www.alppp.ru/court/ vysshie-sudy/06-2010/informacija-o-postanovleniiespch-ot-24-06-2010-po-delu-shalk-i-kopf_ protivavstrii-zha.pdf (дата обращения: 01.09.2018). Загл. с экрана.

10. Постановление Европейского Суда по правам человека по делу «Ольяри и другие против Италии» от 21 июля 2015 г. - Электрон. текстовые дан. Режим доступа: https://subscribe.ru/archive/ law.europeancourt/201511/12104846.html/ (дата обращения: 01.09.2018). - Загл. с экрана.

11. Совместное особое мнение судей Гаджиева, Шикуты, Цоцориа, де Гаэтано и Грицко по делу «Ламбер и другие против Франции» от 5 июня 2015 г. // Правосудие. Судебная практика России. Электрон. текстовые дан. - Режим доступа: http:// www.pravosudie.biz/049941 (дата обращения: 27.08.2018). - Загл. с экрана.

12. Университет Миннесоты. Библиотека по правам человека. - Электрон. текстовые дан. - Режим доступа: http://humanrts.umn.edu/russian/ 
instree/Rzlafchar.html (дата обращения: 10.08.2018). Загл. с экрана.

\section{REFERENCES}

1. Vseobshchaya deklaratsiya ot 10 dekabrya 1948 g. [Universal Declaration of December 10, 1948]. The UN Official Website. URL: http://www.un.org/ru/ documents/decl_conv/declarations/declhr (accessed 9 August 2018).

2. Evropeyskaya konventsiya ot 4 noyabrya 1950 g. [The European Convention of November 4, 1950]. Byulleten mezhdunarodnykh dogovorov, 2001, no. 3 (March).

3. Izbrannye resheniya Evropeyskogo Suda po pravam cheloveka. Voprosy seksualnoy orientatsii $i$ gendernoy identichnosti [Selected Decisions of the European Court of Human Rights. Issues of Sexual Orientation and Gender Identity], p. 4. URL: https:// mhg.ru/sites/default/files/files/izbrre.pdf(accessed 11 August 2018).

4. Kirichek E.V. Stanovlenie i razvitie prav i svobod cheloveka i grazhdanina: filosofsko-pravovoe izmerenie [Formation and Development of Rights and Freedoms of Man and Citizen: Philosophical and Legal Dimension]. Yuridicheskaya nauka i pravookhranitelnaya praktika, 2011, no. 2 (16), p. 15.

5. Mezhdunarodnyy pakt o grazhdanskikh i politicheskikh pravakh ot 16 dekabrya $1966 \mathrm{~g}$. [International Covenant on Civil and Political Rights of December 16, 1966]. Biblioteka Rossiyskoy gazety, 1999, nos 22-23.

6. Postanovlenie Evropeyskogo Suda po pravam cheloveka po delu "Pretti protiv Soedinennogo Korolevstva» ot 29 aprelya $2002 \mathrm{~g}$. [Resolution of the European Court of Human Rights on Case 'Pret vs. the United Kingdom' of April 29, 2002]. URL: http://europeancourt.ru/uploads/ ECHR_Pretty_v_the_United_Kingdom_29_04_2002.pdf (accessed 15 August 2018).

7. Postanovlenie Evropeyskogo Suda po pravam cheloveka po delu «Kokh protiv Germanii» ot
19 iyulya 2012 g. [Resolution of the European Court of Human Rights on Case 'Koch vs. Germany' of July 19, 2012]. Pravosudie. Sudebnaya praktika Rossii [Public Justice. Judicial Practice of Russia]. URL: http:// www.pravosudie.biz/187604 (accessed 31 August 2018).

8. Postanovlenie Evropeyskogo Suda po pravam cheloveka po delu «Lamber i drugie protiv Frantsii» ot 5 iyunya 2015 g. [Resolution of the European Court of Human Rights on Case 'Lambert and Others vs. France' of June 5, 2015]. Pravosudie. Sudebnaya praktika Rossii [Public Justice. Judicial Practice of Russia]. URL: http:// www.pravosudie.biz/049941 (accessed 27 August 2018).

9. Postanovlenie Evropeyskogo Suda po pravam cheloveka po delu «Shalk $i$ Kopf protiv Avstrii» ot 24 iyunya $2010 \mathrm{~g}$. [Resolution of the European Court of Human Rights on Case 'Schalk and Kopf vs. Austria' of June 24, 2010]. URL: http:// www.alppp.ru/court/vysshie-sudy/06-2010/ informacija-o-postanovlenii-espch-ot-24-06-2010-podelu-shalk-i-kopf-protiv-avstrii-zha.pdf (accessed 1 September 2018).

10. Postanovlenie Evropeyskogo Suda po pravam cheloveka po delu "Olyari i drugie protiv Italii» ot 21 iyulya $2015 \mathrm{~g}$. [Resolution of the European Court of Human Rights on Case 'Oliari and Others vs. Italy' of July 21, 2015]. URL: https:// subscribe.ru/archive/law.europeancourt/201511/ 12104846.html/ (accessed 1 September 2018).

11. Sovmestnoe osoboe mnenie sudey Gadzhieva, Shikuty, Tsotsoria, de Gaetano i Gritsko po delu «Lamber i drugie protiv Frantsii» ot 5 iyunya 2015 g. [Joint Dissenting Opinion of Judges Gadzhiev, Shikuta, Tsotsoria, de Gaetano and Gritsko on Case 'Lambert and Others vs. France' of June 5, 2015]. Pravosudie. Sudebnaya praktika Rossii [Public Justice. Judicial Practice of Russia]. URL: http://www.pravosudie.biz/ 049941. (accessed 27 August 2018).

12. Universitet Minnesoty. Biblioteka po pravam cheloveka [University of Minnesota. Human Rights Library]. URL: http://humanrts.umn.edu/russian/ instree/Rzlafchar.html (accessed 10 August 2018).

\section{Information about the Author}

Tatyana V. Goverdovskaya, Candidate of Sciences (Jurisprudence), Associate Professor of Department of International Law, Astrakhan State University, Tatishcheva St., 20A, 414056 Astrakhan, Russian Federation, tara_goya@mail.ru, https://orcid.org/0000-0001-6340-4764

\section{Информация об авторе}

Татьяна Владимировна Говердовская, кандидат юридических наук, доцент кафедры международного права, Астраханский государственный университет, ул. Татищева, 20A, 414056 г. Астрахань, Российская Федерация, tara_goya@mail.ru, https://orcid.org/0000-0001-6340-4764 